\title{
Comparison of Safety and Efficacy of Open, Laparoscopic-Assisted, Totally Laparoscopic, and Robotic Gastrectomy for Gastric Cancer:A Network Meta-Analysis
}

\section{Chao Huang}

Nanchang University Second Affiliated Hospital

Jun Huang

Nanchang University Second Affiliated Hospital

Hongliang Luo

Nanchang University Second Affiliated Hospital

Zhen Zong

Nanchang University Second Affiliated Hospital

Zhengming Zhu ( $D$ zzm8654@163.com )

\section{Research article}

Keywords: Gastric cancer; Surgical approaches; Gastrectomy; Overall morbidity; Harvested lymph nodes; Network meta-analysis

Posted Date: July 24th, 2019

DOI: https://doi.org/10.21203/rs.2.11859/v1

License: (c) (i) This work is licensed under a Creative Commons Attribution 4.0 International License. Read Full License 


\section{Abstract}

Background: Several techniques are used for surgical treatment of gastric cancer (GC), but the efficacy and safety of these approaches have not been compared. Methods: We systematically searched articles of randomized controlled trials (RCTs) through PubMed, Embase, Cochrane Library and ISI-Web of Science databases. The primary outcome was safety using overall morbidity as the main indicator of safety. The secondary outcome was efficacy using the number of harvested lymph nodes (HLNs) as an indicator of efficacy. Multiple surgical treatment comparisons based on Bayesian network integrated the safety and efficacy of all included approaches. The ranking probability was appraised by the probability of the surgical approaches. Results: The 19 eligible RCTs with 4309 patients were included in the network meta-analysis (NMA). There were no differences in overall morbidity between open gastrectomy (OG) and laparoscopic-assisted gastrectomy (LAG) [odds ratio (OR) 1.09, 95\% credible interval (Crl): 0.86-1.64], OG and robotic gastrectomy (RG) (OR 1.16, 95\% Crl: 0.43-3.07), LAG and totally laparoscopic gastrectomy (TLG) (OR 2.85, 95\% Crl: 0.67-12.52), RG and LAG (OR 0.96, 95\% Crl: 0.36-2.93), TLG and OG (OR 0.32, 95\% Crl: 0.07-1.38) and TLG and RG (OR 0.35, 95\% Crl: 0.06-2.01). There were also no differences in the number of HLNs between OG and LAG [weighted mean difference (WMD) 0.91, 95\% Crl: -0.24-2.43)], OG and RG (WMD 1.55, 95\% Crl: -2.58- 5.51), LAG and TLG (WMD -0.90, 95\% Crl: -6.82-5.18), RG and LAG (WMD -0.68, 95\% Crl: -4.63-3.91), TLG and OG (WMD -0.01, 95\% Crl: -6.41-5.90) and TLG and RG (WMD 1.56, 95\% Crl: -6.01-8.59). From the results of the rank probabilities of the four surgical treatments, TLG had the highest probability of being the safest and the most effective surgical approaches. Conclusions: The four surgical treatments of GC have similar safety and efficacy. TLG had the best chance of becoming the safest and most effective treatment.

\section{Background}

Gastric cancer (GC) remains an important cancer worldwide, with more than 1,000,000 new cases in 2018, of which an estimated 783,000 deaths, making it the fifth most commonly diagnosed cancer and the third leading cause of cancer death [1]. Japanese gastric cancer treatment guidelines indicated that distal gastrectomy with D2 lymph node dissection via an open approach is the current standard for advanced gastric cancer (AGC) located in the lower or middle third of the stomach [2]. With the rapid development of laparoscopic instruments and techniques, laparoscopy-assisted distal gastrectomy (LADG) can be used for AGC treatment [3]. Several retrospective studies have demonstrated that totally laparoscopic distal gastrectomy (TLDG) was safer, more feasible, and less invasive than LADG [4-7]. Additionally, Patriti et al. [8] indicated that robot-assisted laparoscopic gastrectomy with D2 lymph node dissection for adenocarcinoma was feasible and safe.

Despite four strategies being available: (OG, $L A G, T L G$, and $R G)$, some of the surgical treatments have never been compared to each other because of the lack of head-to-head trials. Meanwhile, the traditional meta-analysis has some limitations. Thus, the optimum surgical approach for GC is still unknown. We performed a meta-analysis of RCTs by using NMA as a methodology [9]. Safety was used as the primary 
endpoint and efficacy was used as the secondary endpoint. Overall morbidity was defined as within 30 days of surgery.

\section{Methods}

Literature screening was performed according to the preferred reporting items for systematic reviews and meta-analyses (PRISMA) flow chart [10] and the report of the International Society for Pharmacoeconomics and Outcomes Research Task Force on Indirect Treatment Comparisons Good Research Practices [11]. Institutional review board approval was not required.

\section{Search Strategy}

PubMed, Embase, ISI-Web of Science and Cochrane Library were searched for RCTs published between 1950 and 2019. The following terms were used in combinations: Gastric cancer, Stomach Cancer, Gastric Neoplasm, Stomach Neoplasm, Open, Open surgery, Open Procedure, Open Surgical Procedure, HandAssisted Laparoscopic Surgery, Hand Assisted Laparoscopy, Hand-Assisted Laparoscopy, HandAssisted Laparoscopic Surgical Procedures, Robotic Surgical Procedures, Robotic Surgical, Robotic Surgical Procedure, Surgical Procedure, Robotic, Totally laparoscopic, entirely laparoscopic, absolutely laparoscopic, completely laparoscopic, fully laparoscopic, Randomized Controlled Trial, Randomized, and Randomly.

\section{Study Selection}

The only criterion for eligibility was the RCTs comparing at least 2 of the following strategies: open, laparoscopic-assisted, totally laparoscopic, and robotic gastrectomy for GC. Duplicate studies were removed using EndNote version X7.7 (Thomson Reuters). Additionally, for eligibility, the patient underwent radical gastrectomy. Studies that fulfilled the eligibility criteria were evaluated in full-text form. We exclude studies that are not RCTs and unavailable data.

\section{Data Collection and Assessment of Risk of Bias}

The data were extracted by two reviewers independently using the same standardized collection form. Relevant data were collected, including the first author, the year of publication, country, patient characteristics, treatment approaches, the sample size and outcomes (overall morbidity, the number of HLNs, total blood loss, length of hospital stay, operative time, pulmonary and anastomotic complications). Qualitative assessment was accomplished by two investigators independently, and if there were disagreements, it will be discussed with the third investigator. Qualitative assessment of the articles was conducted using the Cochrane Collaboration tool for assessing the risk of bias in randomized trials [12]. 


\section{Statistical Analysis}

The primary outcome criterion of our NMA was overall morbidity, and the secondary outcome measure was the number of HLNs. The treatment effect of dichotomous data was expressed as OR. The treatment effect of continuous (mean difference) data was expressed as WMD. 95\% Cls were used for the direct meta-analysis and Crl for the estimates of the NMA.

Heterogeneity was assessed by the Cochran Q test and measured by the $\mathrm{I}^{2}$ statistic. Interpretation of the $1^{2}$ values was performed by assigning low, moderate, and high attributes in cases showing values of $0 \%$ to $25 \%, 25 \%$ to $50 \%$, and above $75 \%$, respectively.

First, we performed a traditional pair-wise meta-analysis with Review Manager (RevMan. Version 5.3.Copenhagen: The Nordic Cochrane Centre, The Cochrane Collaboration, 2014), synthesizing studies that compared the same surgical approach with a fixed-effect model.

Second, we built a random-effects network within a Bayesian framework using Markov chain Monte Carlo methods in ADDIS 1.16.8 (Drugis.org) [13], three different sets of starting values to fit the model, yielding 100,000 iterations $(50,000$ per chain) to obtain the posterior distributions of model parameters. For overall morbidity and the number of HLNs, we used 5000 burn-ins and a thinning interval of 50 for each chain. We also estimated the probability that each of the treatments was the best approach, by calculating the OR for each surgical approach compared with an arbitrary common control group, and counting the proportion of iterations of the Markov chain of the OR ranking in treatments.

A variance calculation and a node-splitting analysis provided by the software ADDIS 1.16.8 were applied to assess inconsistency between indirect and direct comparisons in closed loops, or the comparison was used to confirm the inconsistency in a lack of a closed loop. The $95 \% \mathrm{Crl}$ of the OR and WMD were used for the estimates in the above calculations. Network plot generation and publication bias were performed with Stata 14.2 (StataCorp, College Station, TX). Risk of bias was assessed using the dedicated Cochrane tool of Review Manager.

\section{Results}

\section{Study selection and characteristics}

The literature screening process is shown in Fig. 1. A total of 1120 records were identified from various databases, including PubMed, Embase, Cochrane Library and ISI-Web of Science; 223 records were excluded because the title showed that they were identical. Among the remaining 897 studies, 807 were excluded because, according to the title and abstract screening, the field of these studies was not relevant. Ninety full-text articles were considered; among these studies, 71 were removed for the following reasons: 8 were conference abstracts, 45 were review articles, 3 were not RCTs, 3 were case reports, and 
12 reported unextractable data. Finally, 19 studies [3,14-31] were included for quality evaluation and quantitative analysis.

The characteristics of the included studies are shown in Table 1. Our analysis included 4309 patients treated in four surgical treatments: 2092 treated with OG, 2011 treated with LAG, 151 treated with RG, and 55 treated with TLG. Fig. 2 shows the network plot of the comparison of four surgical treatments.

\section{Comparisons of overall morbidity}

The results of pair-wise meta-analyses are showed in Table 2. The heterogeneity and the forest plot of the results are summarized in Fig. 3. There were no differences between OG and LAG (OR 1.02, 95\% Cl: 0.861.20; $P=0.85$; heterogeneity: $\mathrm{Chi}^{2}=18.95, \mathrm{P}=0.27, \mathrm{I}^{2}=16 \%$ ), OG and RG (OR 1.13, 95\% Cl: 0.52-2.43; $P=0.76)$ and $L A G$ and TLG (OR 2.49, 95\% Cl: $0.72-8.65 ; P=0.15)$. The results of NMA are presented in Table 3. In the NMA, there were no statistically significant differences between OG and LAG (OR 1.09, 95\% Crl: 0.86-1.64), OG and RG (OR 1.16, 95\% Crl: 0.43-3.07), LAG and TLG (OR 2.85, 95\% Crl: 0.67-12.52), RG and LAG (OR 0.96, 95\% Crl: 0.36-2.93), TLG and OG (OR 0.32, 95\% Crl: 0.07-1.38) and TLG and RG (OR $0.35,95 \% \mathrm{Crl}: 0.06-2.01)$. The results of the rank probabilities of the four surgical approaches are summarized in Fig. 4 and Table 4, demonstrating that TLG had the highest probability of being the safest surgical approaches.

\section{Comparisons of the number of HLNs}

The results of pair-wise meta-analyses are presented in Table $\mathbf{5}$. The heterogeneity and the forest plot of the results are summarized in Fig. 5. There were no differences between OG and LAG (WMD 0.01, 95\% Cl: -0.52-0.55; $P=0.96$; heterogeneity: $\mathrm{Chi}^{2}=12.30, \mathrm{P}=0.42, \mathrm{I}^{2}=2 \%$ ), OG and RG (WMD 1.60, 95\% Cl: -0.69-3.89; $\mathrm{P}=0.17$ ) and LAG and TLG (WMD $-0.90,95 \% \mathrm{Cl}:-5.92-4.12 ; \mathrm{P}=0.73$ ). The results of NMA are presented in Table 6. In the NMA, there were no statistically significant differences between OG and LAG (WMD 0.91, 95\% Crl: -0.24-2.43), OG and RG (WMD 1.55, 95\% Crl: -2.58- 5.51), LAG and TLG (WMD -0.90, 95\% Crl: -6.82-5.18), RG and LAG (WMD -0.68, 95\% Crl: -4.63- 3.91), TLG and OG (WMD -0.01, 95\% Crl: -6.41-5.90) and TLG and RG (WMD 1.56, 95\% Crl: -6.01-8.59). The results of the rank probabilities of the four surgical treatments in terms of the number of HLNs are summarized in Fig. 6 and Table 7, indicating that TLG had the highest probability of being the most effective treatment.

\section{Quality of evidence}

The assessment of the risk of bias for eligible RCTs included in the NMA is presented in Fig. 7 according to the Cochrane risk-of-bias tool, indicating no severe risk of bias. The heterogeneity of pair-wise 
comparison between the two surgical procedures is shown in Table 2 and Table 5, and no significant heterogeneity was detected. The publication bias using Begg's $(P=0.091)$ and Egger's $(P=0.001)$ test showed that there may be some publication bias (Fig. 8). Because of the lack of a closed loop, the comparison was used to confirm the inconsistency. The results of inconsistency are summarized in Table 8. The results of the $95 \% \mathrm{Crl}$ of random effects standard deviation of consistency are very similar to the inconsistency, suggesting consistency within the model.

\section{Sensitivity analysis}

Sensitivity analysis was performed for the group with low heterogeneity, which suggested that the included study estimates were basically within the $\mathrm{Cl}$ of the total effect values, indicating that the results were relatively stable (Fig. 9).

\section{Discussion}

GC is the third leading cause of cancer death and surgical resection is still the best treatment in the current medical care sitting [32]. Surgery is the most effective treatment for GC. Due to the lack of headto-head trials and the limitations of traditional meta-analysis methods, a clear statement on the best surgical approaches for $\mathrm{GC}$ remains unknown. This study is the first, to our knowledge, to compare the 4 surgical approaches available for the treatment of GC by using an NMA. This NMA combined direct and indirect evidence from 19 RCTs including 4309 patients with GC to estimate the relative safety and efficacy of 4 surgical approaches for outcomes involving overall morbidity and the number of HLNs.

Since its introduction in 1994, minimally invasive gastrectomy (MIG) has become widely performed for the treatment of GC worldwide [33]. The advantages of minimally invasive surgery are reduced blood loss, promoted postoperative recovery, shorter hospital stay, and diminished morbidity [34-36]. However, our studies showed that 4 strategies, namely, OG, LAG, TLG, and RG, had no statistically significant differences for overal/ morbidity, which is consistent with some previous studies [14-24, 26-30]. The results of the rank probabilities of the 4 surgical treatments, demonstrated that TLG had the highest probability of being the safest surgical approaches.

Since 1999, with the first report of laparoscopy-assisted total gastrectomy plus lymph node dissection for GC [37], laparoscopic gastrectomy has been widely used in Japan and Korea to treat GC. However, the application of laparoscopic techniques in AGC is still controversial because of the technical difficulty of extragastric lymphadenectomy and the lack of data related to the procedure's oncologic adequacy. In previous study analysis of patients undergoing MIG versus OG, MIG was associated with equivalent oncologic outcomes [38]. Meanwhile, a recent study showed that MIG can be safely introduced regarding short-term oncological outcomes, with a proctoring program [39]. Multiple randomized trials have demonstrated the oncology equivalence of laparoscopic and open gastrectomy [20, 22, 40-43]. Previous studies have shown that there were no significant differences in the total number of HLNs between the 
LADG and OG $[44,45]$. They believed that LADG with D2 lymph node dissection is oncologically consistent with OG. Recently, Yu et al. [29] concluded that there was no difference in 3-year disease-free survival between LAG and OG in patients with locally AGC through a multicenter randomized controlled trial.

In addition, previous studies $[4,5]$ have shown that there was no statistically significant difference between the LADG and TLDG groups for the number of HLNs, but the latter was superfluous. Kim et al. [6] compared 268 patients undergoing LADG with 180 patients undergoing TLDG, and they found that there was a statistically significant difference in the number of HLNs, demonstrating that TLDG harvested more lymph nodes than TADG. However $\square$ this present study showed similar results wherein 4 surgical treatments for GC have no statistically significant differences for the number of HLNs and TLG had the highest probability of being the most effective treatment based on the results of the rank probabilities of the 4 surgical approaches.

\section{Limitations}

This NMA is acknowledged to have several limitations. First, the number and sample size of the included studies were still inadequate and all networks had not one closed loop so that a node-splitting analysis was not possible. Second, differences in tumor staging, tumor location and the number of examined lymph nodes in each trial may have an effect on the results. Third, this study was not registered and there may be some publication bias, but we still follow the steps of the systematic review strictly. Finally, some secondary outcomes, such as total blood loss, length of hospital stay, operative time, pulmonary and anastomotic complications, were not analyzed. Therefore, future head-to-head RCTs are necessary to investigate the optimal surgical treatment for GC.

\section{Conclusion}

This present study is the first to compare the 4 surgical treatments available for GC by using an NMA and demonstrated that the four surgical treatments of GC have similar safety and efficacy $\triangle T L G$ had the best chance of becoming the safest and most effective treatment. Further clinical studies are needed to evaluate the safety and efficacy of TLG for GC.

\section{Abbreviations}

GC: gastric cancer; RCTs: randomized controlled trials; HLNs: harvested lymph nodes; NMA: network meta-analysis; OG: open gastrectomy; LAG: laparoscopic-assisted gastrectomy; OR: odds ratio; Crl: credible interval; RG: robotic gastrectomy; TLG: totally laparoscopic gastrectomy; WMD: weighted mean difference; AGC: advanced gastric cancer; LADG: laparoscopy-assisted distal gastrectomy ; TLDG :totally laparoscopic distal gastrectomy; PRISMA: preferred reportingitems for systematic reviews and metaAnalyses; MIG :minimally invasive gastrectomy 


\section{Declarations}

\section{Acknowledgments}

Not applicable.

\section{Author contributors}

Zhengming Zhu and Chao Huang designed the study. Hongliang Luo and Chao Huang screened studies and extracted data. Disagreements were resolved by discussion with Jun Huang. Chao Huang performed the statistical analyses. Zhengming Zhu, Jun Huang, Hongliang Luo, Zhen Zong and Chao Huang reviewed the results, interpreted the data, and wrote the manuscript. All authors read and approved the final version of the paper.

\section{Funding}

Not applicable.

\section{Availability of data and materials}

The datasets analysed during this study are available from the corresponding author on reasonable request.

\section{Ethics approval and consent to participate}

Formal ethics approval is not required for a systematic review.

\section{Consent for publication}

Not applicable.

\section{Competing interests}

The authors declare that they have no competing interests. 


\section{Author details}

${ }^{1}$ Department of Gastrointestinal Surgery, The Second Affiliated Hospital of Nanchang University, No. 1 Minde Road, Nanchang, 330000, Jiangxi, China.

\section{References}

1. Bray F, Ferlay J, Soerjomataram I, Siegel RL, Torre LA and Jemal A. Global cancer statistics 2018(2018): GLOBOCAN estimates of incidence and mortality worldwide for 36 cancers in 185 countries. CA Cancer J Clin.

2. Japanese gastric cancer treatment guidelines 2010 (ver. 3)(2011) Gastric cancer : official journal of the International Gastric Cancer Association and the Japanese Gastric Cancer Association. 14:11323.

3. Park YK, Yoon HM, Kim YW, Park JY, Ryu KW, Lee YJ, Jeong O, Yoon KY, Lee JH, Lee SE, Yu W, Jeong SH, Kim T, Kim S, Nam BH and group C(2018) Laparoscopy-assisted versus Open D2 Distal Gastrectomy for Advanced Gastric Cancer: Results From a Randomized Phase II Multicenter Clinical Trial (COACT 1001). Annals of surgery. 267:638-645.

4. Ikeda O, Sakaguchi Y, Aoki Y, Harimoto N, Taomoto J, Masuda T, Ohga T, Adachi E, Toh Y, Okamura T and Baba H(2009)Advantages of totally laparoscopic distal gastrectomy over laparoscopically assisted distal gastrectomy for gastric cancer. Surgical endoscopy. 23:2374-9.

5. Song KY, Park CH, Kang HC, Kim J-J, Park SM, Jun KH, Chin HM and Hur H(2008)Is Totally Laparoscopic Gastrectomy Less Invasive Than Laparoscopy-assisted Gastrectomy?: Prospective, Multicenter Study. Journal of Gastrointestinal Surgery. 12:1015-1021.

6. Kim BS, Yook JH, Choi YB, Kim KC, Kim MG, Kim TH, Kawada H and Kim BS(2011)Comparison of Early Outcomes of Intracorporeal and Extracorporeal Gastroduodenostomy After Laparoscopic Distal Gastrectomy for Gastric Cancer. Journal of Laparoendoscopic \& Advanced Surgical Techniques. 21:387-391

7. Sugimoto M, Kinoshita T, Shibasaki H, Kato Y, Gotohda N, Takahashi S and Konishi M(2013) Shortterm outcome of total laparoscopic distal gastrectomy for overweight and obese patients with gastric cancer. Surgical endoscopy. 27:4291-6.

8. Patriti A, Ceccarelli G, Bellochi R, Bartoli A, Spaziani A, Di Zitti L and Casciola L(2008) Robot-assisted laparoscopic total and partial gastric resection with $\mathrm{D} 2$ lymph node dissection for adenocarcinoma. Surgical endoscopy. 22:2753-60.

9. Cipriani A, Higgins J, Geddes J and Salanti G(2013)Conceptual and technical challenges in network meta-analysis. Ann Intern Med. 159:130-7.

10. Moher D, Liberati A, Tetzlaff J, Altman DG (2009) Preferred reporting items for systematic reviews and meta-analyses: the PRISMA statement. Ann Intern Med 151(4):264-269. 
11. Jansen JP, Fleurence R, Devine B, Itzler R, Barrett A, Hawkins N, Lee K, Boersma C, Annemans L, Cappelleri JC (2011) Interpreting indirect treatment comparisons and network meta-analysis for health-care decision making: report of the ISPOR Task Force on Indirect Treatment Comparisons Good Research Practices: part 1. Value Health 14(4):417-428.

12. Higgins JP, Altman DG, Gotzsche PC, Juni P, Moher D, Oxman AD, Savovic J, Schulz KF, Weeks L, Sterne JA, Cochrane Bias Methods $G$ and Cochrane Statistical Methods G(2011)The Cochrane Collaboration's tool for assessing risk of bias in randomised trials. BMJ. 343:d5928.

13. van Valkenhoef G, Tervonen T, Zwinkels T, de Brock B and Hillege H(2013)ADDIS: A decision support system for evidence-based medicine. Decision Support Systems. 55:459-475.

14. Aoyama T, Yoshikawa T, Hayashi T, Hasegawa S, Tsuchida K, Yamada T, Cho H, Ogata T, Fujikawa H, Yukawa N, Oshima T, Rino Y and Masuda M(2014)Randomized comparison of surgical stress and the nutritional status between laparoscopy-assisted and open distal gastrectomy for gastric cancer. Annals of surgical oncology. 21:1983-90.

15. Cai J, Wei D, Gao CF, Zhang CS, Zhang H and Zhao T(2011)A prospective randomized study comparing open versus laparoscopy-assisted D2 radical gastrectomy in advanced gastric cancer. Digestive surgery. 28:331-7.

16. Cui M, Li Z, Xing J, Yao Z, Liu M, Chen L, Zhang C, Yang H, Zhang N, Tan F, Jiang B, Di J, Wang Z, Ji J and Su X(2015)A prospective randomized clinical trial comparing D2 dissection in laparoscopic and open gastrectomy for gastric cancer. Medical oncology (Northwood, London, England). 32:241.

17. Fujii K, Sonoda K, Izumi K, Shiraishi N, Adachi Y and Kitano S(2003)T lymphocyte subsets and Th1/Th2 balance after laparoscopy-assisted distal gastrectomy. Surgical endoscopy. 17:1440-4.

18. Hayashi $H$, Ochiai T, Shimada $H$ and Gunji $Y(2005)$ Prospective randomized study of open versus laparoscopy-assisted distal gastrectomy with extraperigastric lymph node dissection for early gastric cancer. Surgical endoscopy. 19:1172-6.

19. Hu Y, Huang C, Sun Y, Su X, Cao H, Hu J, Xue Y, Suo J, Tao K, He X, Wei H, Ying M, Hu W, Du X, Chen P, Liu H, Zheng C, Liu F, Yu J, Li Z, Zhao G, Chen X, Wang K, Li P, Xing J and Li G(2016)Morbidity and Mortality of Laparoscopic Versus Open D2 Distal Gastrectomy for Advanced Gastric Cancer: A Randomized Controlled Trial. Journal of clinical oncology : official journal of the American Society of Clinical Oncology. 34:1350-7.

20. Huscher CGS, Mingoli A, Sgarzini G, Sansonetti A, Di Paola M, Recher A and Ponzano C(2005) Laparoscopic Versus Open Subtotal Gastrectomy for Distal Gastric Cancer. Annals of surgery. 241:232-237.

21. Luo G, Cao Y, Gong J, Wang X, Wang B, Zhou J and Li Y (2017) Hand-assisted laparoscopic versus open surgery radical gastrectomy for advanced distal gastric cancer: a prospective randomized study. International Journal of Clinical \& Experimental Medicine.10:5001-5010.

22. Kim HH, Hyung WJ, Cho GS, Kim MC, Han SU, Kim W, Ryu SW, Lee HJ and Song KY(2010)Morbidity and mortality of laparoscopic gastrectomy versus open gastrectomy for gastric cancer: an interim 
report-a phase III multicenter, prospective, randomized Trial (KLASS Trial). Annals of surgery. 251:417-20.

23. Kim YW, Yoon HM, Yun YH, Nam BH, Eom BW, Baik YH, Lee SE, Lee Y, Kim YA, Park JY and Ryu KW(2013) Long-term outcomes of laparoscopy-assisted distal gastrectomy for early gastric cancer: result of a randomized controlled trial (COACT 0301). Surgical endoscopy. 27:4267-76.

24. Kitano S, Shiraishi N, Fujii K, Yasuda K, Inomata M and Adachi Y(2002)A randomized controlled trial comparing open vs laparoscopy-assisted distal gastrectomy for the treatment of early gastric cancer: An interim report. Surgery. 131:S306-S311.

25. Lee $\mathrm{JH}$, Han HS and Lee $\mathrm{JH}(2005) \mathrm{A}$ prospective randomized study comparing open vs laparoscopyassisted distal gastrectomy in early gastric cancer: early results. Surgical endoscopy. 19:168-73.

26. Sakuramoto S, Yamashita K, Kikuchi S, Futawatari N, Katada N, Watanabe M, Okutomi T, Wang G and Bax L(2013)Laparoscopy versus open distal gastrectomy by expert surgeons for early gastric cancer in Japanese patients: Short-term clinical outcomes of a randomized clinical trial. Surgical Endoscopy and Other Interventional Techniques. 27:1695-1705.

27. Shi Y, Xu X, Zhao Y, Qian F, Tang B, Hao Y, Luo H, Chen J and Yu P(2018)Short-term surgical outcomes of a randomized controlled trial comparing laparoscopic versus open gastrectomy with D2 lymph node dissection for advanced gastric cancer. Surgical endoscopy. 32:2427-2433.

28. Takiguchi S, Fujiwara Y, Yamasaki M, Miyata H, Nakajima K, Sekimoto M, Mori M and Doki Y(2013) Laparoscopy-assisted distal gastrectomy versus open distal gastrectomy. A prospective randomized single-blind study. World journal of surgery. 37:2379-86.

29. Yu J, Huang C, Sun Y, Su X, Cao H, Hu J(2019) Effect of Laparoscopic vs Open Distal Gastrectomy on 3-Year Disease-Free Survival in Patients With Locally Advanced Gastric Cancer: The CLASS-01 Randomized Clinical Trial. Jama .321:1983-92.

30. Wang G, Jiang Z, Zhao J, Liu J, Zhang S, Zhao K, Feng X and Li J(2016)Assessing the safety and efficacy of full robotic gastrectomy with intracorporeal robot-sewn anastomosis for gastric cancer: $A$ randomized clinical trial. Journal of surgical oncology. 113:397-404.

31. Woo J, Lee JH, Shim KN, Jung HK, Lee HM and Lee HK(2015)Does the Difference of Invasiveness between Totally Laparoscopic Distal Gastrectomy and Laparoscopy-Assisted Distal Gastrectomy Lead to a Difference in Early Surgical Outcomes? A Prospective Randomized Trial. Annals of surgical oncology. 22:1836-43.

32. Etoh T, Inomata M, Shiraishi N and Kitano S(2013)Minimally invasive approaches for gastric cancerJapanese experiences. Journal of surgical oncology. 107:282-8.

33. Kitano S, Iso Y, Moriyama M and Sugimachi K(1994)Laparoscopy-assisted Billroth I gastrectomy. Surgical laparoscopy \& endoscopy.4: 146-148.

34. Jiang L, Yang KH, Guan QL, Cao N, Chen Y, Zhao P, Chen YL and Yao L(2013)Laparoscopy-assisted gastrectomy versus open gastrectomy for resectable gastric cancer: an update meta-analysis based on randomized controlled trials. Surgical endoscopy. 27:2466-80. 
35. Haverkamp L, Weijs TJ, van der Sluis PC, van der Tweel I, Ruurda JP and van Hillegersberg R(2013) Laparoscopic total gastrectomy versus open total gastrectomy for cancer: a systematic review and meta-analysis. Surgical endoscopy. 27:1509-20.

36. Kodera Y, Fujiwara M, Ohashi N, Nakayama G, Koike M, Morita S and Nakao A(2010)Laparoscopic surgery for gastric cancer: a collective review with meta-analysis of randomized trials. Journal of the American College of Surgeons. 211:677-86.

37. Uyama I, Sugioka A, Fujita J, Komori Y, Matsui H and Hasumi A(1999)Laparoscopic total gastrectomy with distal pancreatosplenectomy and D2 lymphadenectomy for advanced gastric cancer. Gastric cancer : official journal of the International Gastric Cancer Association and the Japanese Gastric Cancer Association. 2:230-234.

38. Leung K, Sun Z, Nussbaum DP, Adam MA, Worni M and Blazer DG(2017)3rd. Minimally invasive gastrectomy for gastric cancer: A national perspective on oncologic outcomes and overall survival. Surgical oncology. 26:324-330.

39. Brenkman HJF, Ruurda JP, Verhoeven RHA and van Hillegersberg R(2017)Safety and feasibility of minimally invasive gastrectomy during the early introduction in the Netherlands: short-term oncological outcomes comparable to open gastrectomy. Gastric cancer: official journal of the International Gastric Cancer Association and the Japanese Gastric Cancer Association. 20:853-860.

40. Kim W, Kim HH, Han SU, Kim MC, Hyung WJ, Ryu SW, Cho GS, Kim CY, Yang HK, Park DJ, Song KY, Lee SI, Ryu SY, Lee JH and Lee HJ(2016)Decreased Morbidity of Laparoscopic Distal Gastrectomy Compared With Open Distal Gastrectomy for Stage I Gastric Cancer: Short-term Outcomes From a Multicenter Randomized Controlled Trial (KLASS-01). Annals of surgery. 263:28-35.

41. Kitano S, Shiraishi N, Fujii K, Yasuda K, Inomata M and Adachi Y(2002)A randomized controlled trial comparing open vs laparoscopy-assisted distal gastrectomy for the treatment of early gastric cancer: An interim report. Surgery. 131:S306-S311.

42. Lee $\mathrm{JH}$, Han HS and Lee JH(2005)A prospective randomized study comparing open vs laparoscopyassisted distal gastrectomy in early gastric cancer: early results. Surgical endoscopy. 19:168-73.

43. Kim YW, Baik YH, Yun YH, Nam BH, Kim DH, Choi IJ and Bae JM(2008)Improved quality of life outcomes after laparoscopy-assisted distal gastrectomy for early gastric cancer: results of a prospective randomized clinical trial. Annals of surgery. 248:721-7.

44. Huscher C, Mingoli A, Sgarzini G, Sansonetti A, Piro F, Ponzano C and Brachini G(2005)Value of extended lymphadenectomy in laparoscopic subtotal gastrectomy for advanced gastric cancer. Journal of the American College of Surgeons.200:314.

45. Song KY, Kim SN and Park CH(2008)Laparoscopy-assisted distal gastrectomy with D2 lymph node dissection for gastric cancer: technical and oncologic aspects. Surgical endoscopy. 22:655-9.

\section{Figure Titles And Legends}

Fig. 1 Study flow diagram. 
Fig. 2 Network of the comparisons for the Bayesian network meta-analysis.

The sizes of the nodes and the thicknesses of the edges are weighted according to the number of studies evaluating each treatment and direct comparison, respectively.

Fig. 3 Forest plots of results with pair-wise meta-analysis for four gastrectomy of overall morbidity.

Fig. 4 Ranking of treatments in overall morbidity.

Fig. 5 Forest plots of results with pair-wise meta-analysis for four gastrectomy of HLNs.

Fig. 6 Ranking of treatments in the number of HLNs.

Fig. 7 Risk of bias graph for all studies included.

Fig. 8 Begg's funnel plot.

Fig. 9 Sensitivity analysis for the group with low heterogeneity.

\section{Figures}




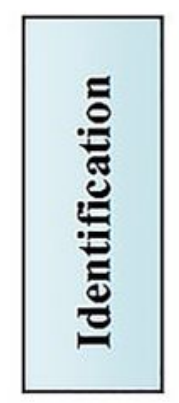

$$
\begin{aligned}
& 1120 \text { Records identified through PubMed, EMBASE, } \\
& \text { Cochrane Library, ISI-Web of science }
\end{aligned}
$$

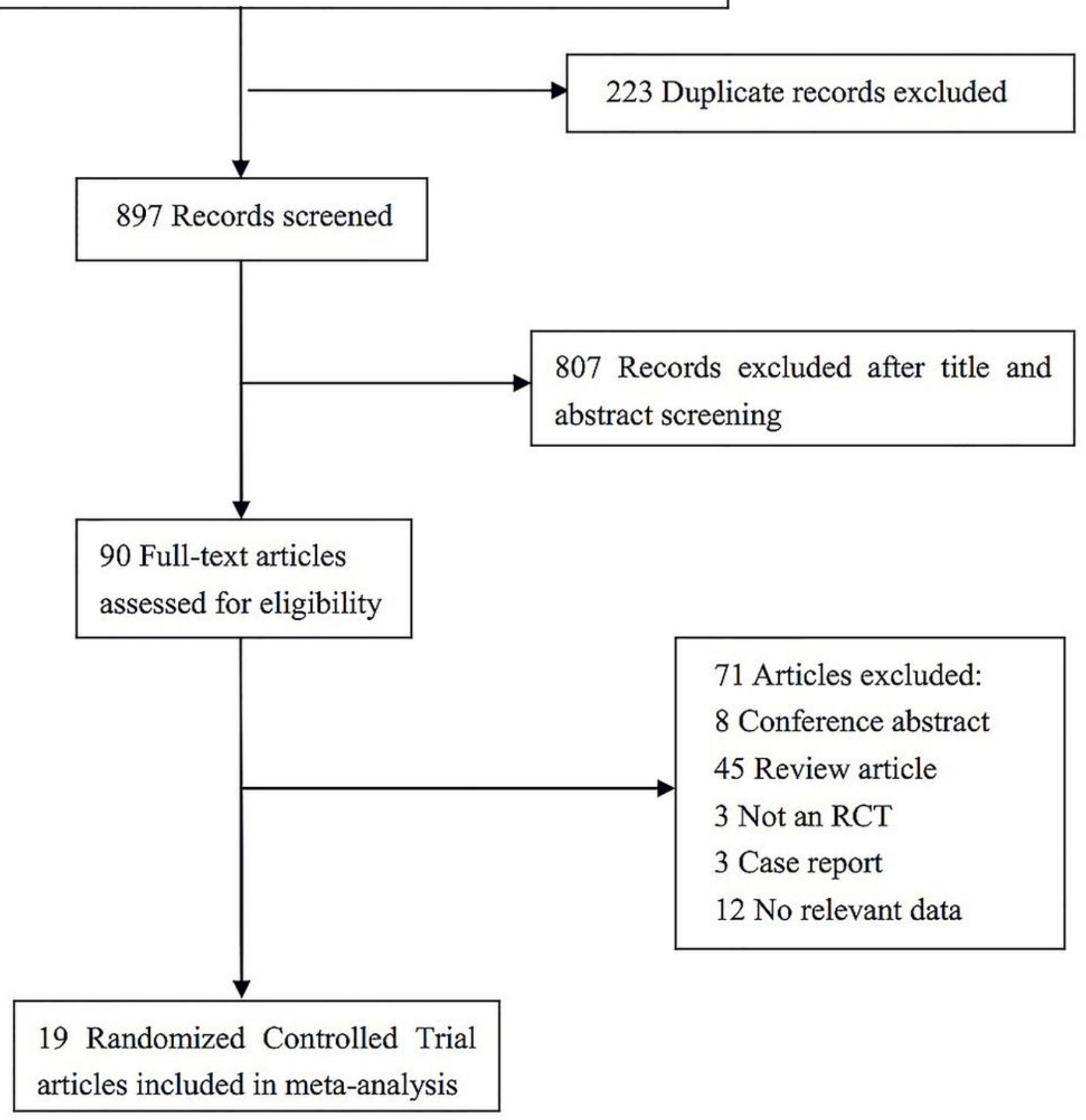

Fig. 1 Study flow diagram

Figure 1

Study flow diagram. 


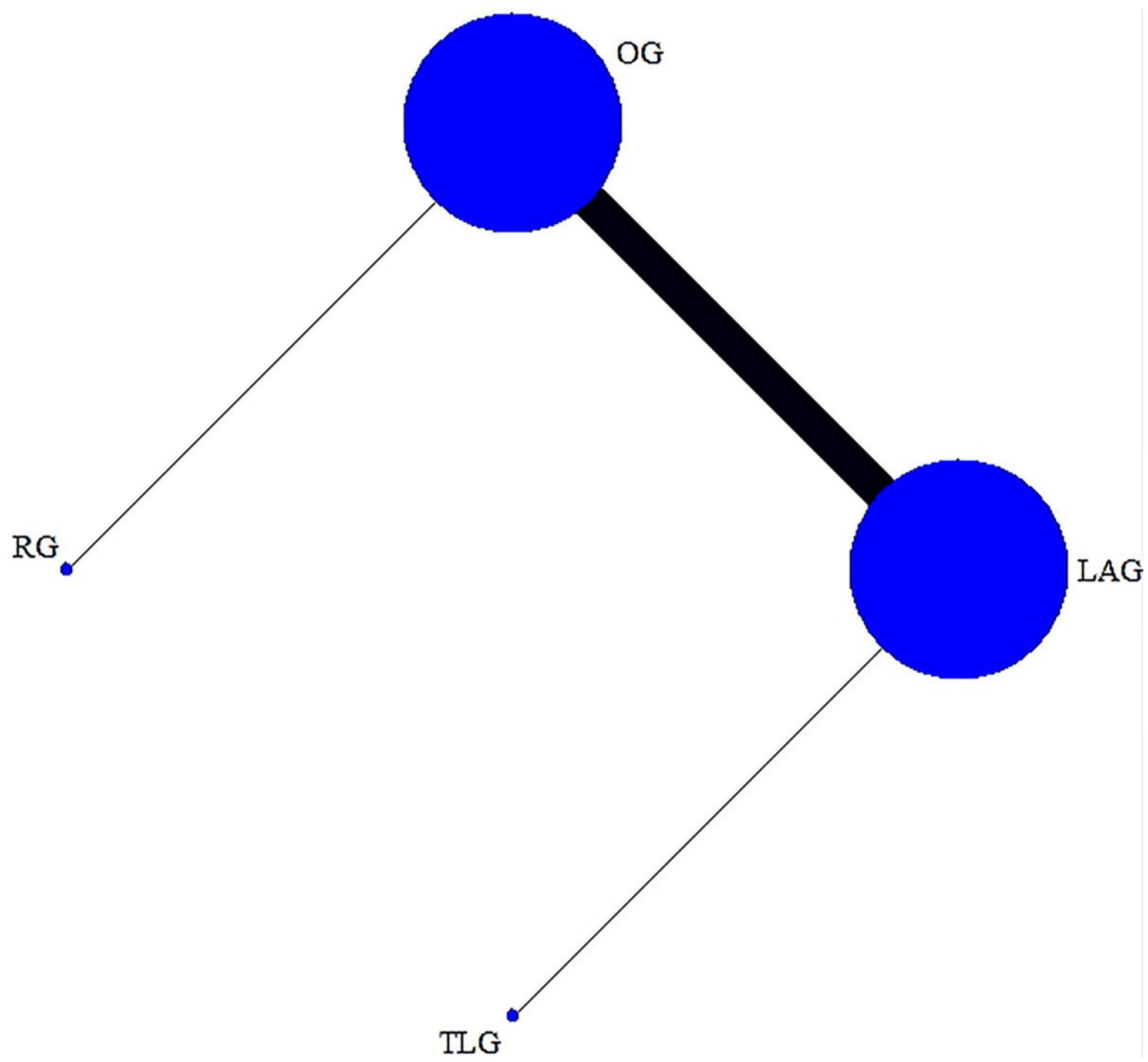

\section{Figure 2}

Network of the comparisons for the Bayesian network meta-analysis. The sizes of the nodes and the thicknesses of the edges are weighted according to the number of studies evaluating each treatment and direct comparison, respectively. 
OG

LAG

Stuchy or Subgroup Events Total Events Total Weight M-H, Fixed, 95\% C

\begin{tabular}{|c|c|c|c|c|c|c|}
\hline Aoyama 2014 & 1 & 13 & 1 & 13 & $0.3 \%$ & $1.00[0.06,17.90]$ \\
\hline Cai 2011 & 9 & 47 & 6 & 49 & $1.7 \%$ & $1.70[0.55,5.21]$ \\
\hline Cui 2015 & 27 & 142 & 28 & 128 & $8.4 \%$ & $0.84[0.46,1.52]$ \\
\hline Fujii 2003 & 2 & 10 & 2 & 10 & $0.6 \%$ & $1.00[0.11,8.9$ \\
\hline Hayashi 2005 & 8 & 14 & 4 & 14 & $0.6 \%$ & $3.33[0.69,16.0$ \\
\hline Hu 2016 & 67 & 520 & 79 & 519 & $24.2 \%$ & $0.82[0.58,1.1$ \\
\hline Huscher 2005 & 8 & 29 & 7 & 30 & $1.8 \%$ & $1.25[0.39,4.0$ \\
\hline Kim H 2010 & 27 & 163 & 20 & 179 & $5.6 \%$ & $1.58[0.85,2.9$ \\
\hline Kim Y 2013 & 8 & 82 & 7 & 82 & $2.2 \%$ & $1.16[0.40,3.3$ \\
\hline Kitano 2002 & 4 & 14 & 2 & 14 & $0.5 \%$ & $2.40[0.36,15.9$ \\
\hline Lee 2005 & 10 & 23 & 3 & 24 & $0.6 \%$ & $5.38[1.25,23.2$ \\
\hline Luo 2017 & 6 & 62 & 5 & 62 & $1.6 \%$ & $1.22[0.35,4.2$ \\
\hline Park 2017 & 18 & 96 & 17 & 100 & $4.8 \%$ & $1.13[0.54,2.3$ \\
\hline Sakuramoto 2013 & 5 & 32 & 1 & 31 & $0.3 \%$ & $5.56[0.61,50.6$ \\
\hline Shi 2017 & 23 & 160 & 19 & 162 & $5.7 \%$ & $1.26[0.66,2.4$ \\
\hline Takiguchi 2013 & 2 & 20 & 0 & 20 & $0.2 \%$ & $5.54[0.25,123.0$ \\
\hline Yu 2019 & 139 & 520 & 159 & 519 & $41.0 \%$ & $0.83[0.63,1.0$ \\
\hline Total (95\% Cl) & \multicolumn{3}{|c|}{1947} & 1956 & $100.0 \%$ & $1.02[0.86,1.2$ \\
\hline Total events & 364 & & 360 & & & \\
\hline \multicolumn{7}{|c|}{ Heterogeneity: $\mathrm{Chi}^{2}=18.95, \mathrm{df}=16(P=0.27) ; \mathrm{I}^{2}=16 \%$} \\
\hline
\end{tabular}

LAG TLG

Oddls Ratio

Stucty or Subgroup Events Total Events Total Weight M-H, Fixed, 95\% CI $\begin{array}{lllllll}\text { Woo } 2015 & 9 & 55 & 4 & 55 & 100.0 \% & 2.49 \\ {[0.72,8.65]}\end{array}$

Total $(95 \% \mathrm{Cl})$

55

Total events

9

Heterogeneity: Not applicable

Test for overall effect: $Z=1.44(P=0.15)$
Oddls Ratio

M-H, Fixed, $95 \% \mathrm{Cl}$

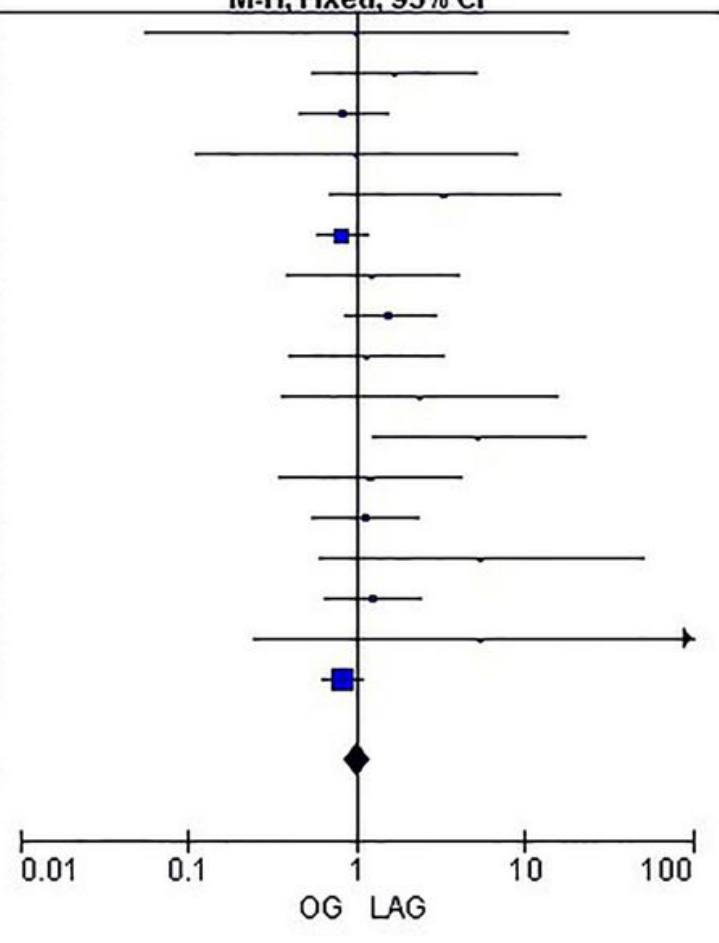

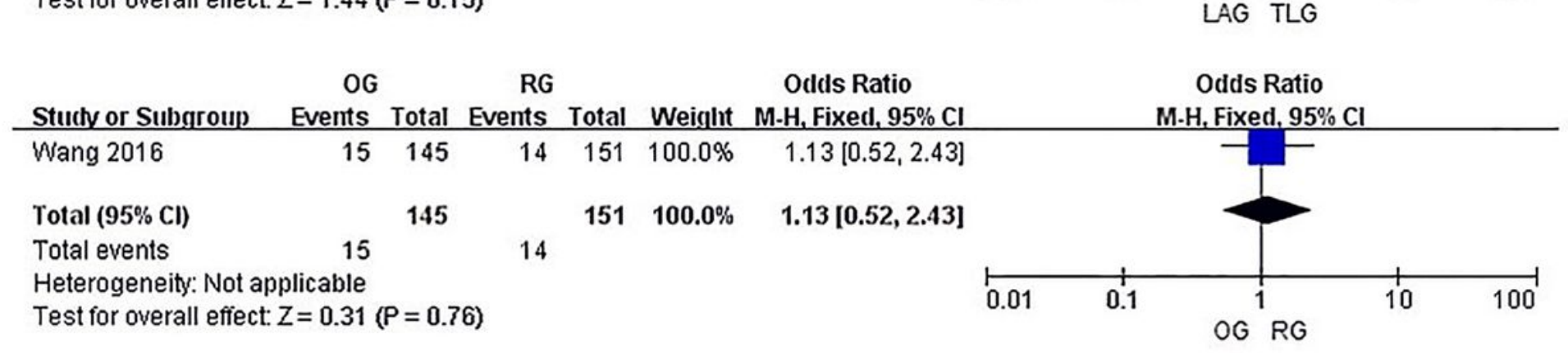

\section{Figure 3}

Forest plots of results with pair-wise meta-analysis for four gastrectomy of overall morbidity. 


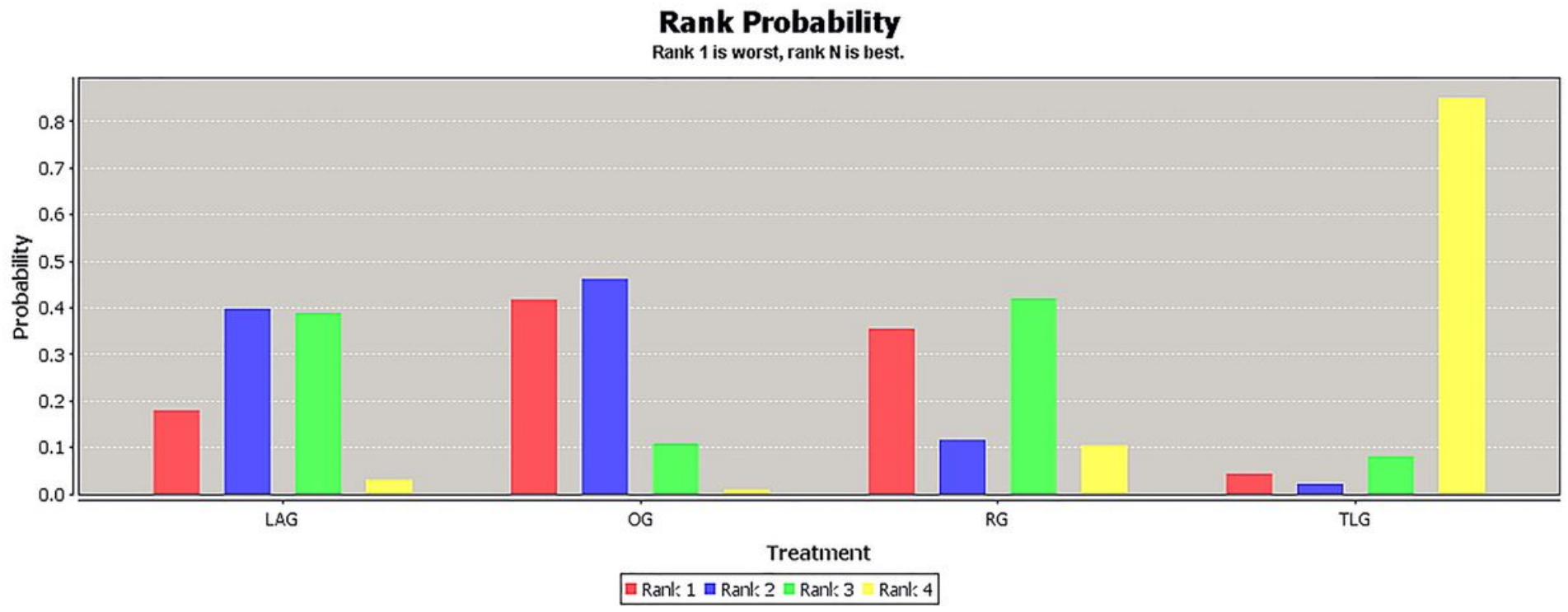

Figure 4

Ranking of treatments in overall morbidity.

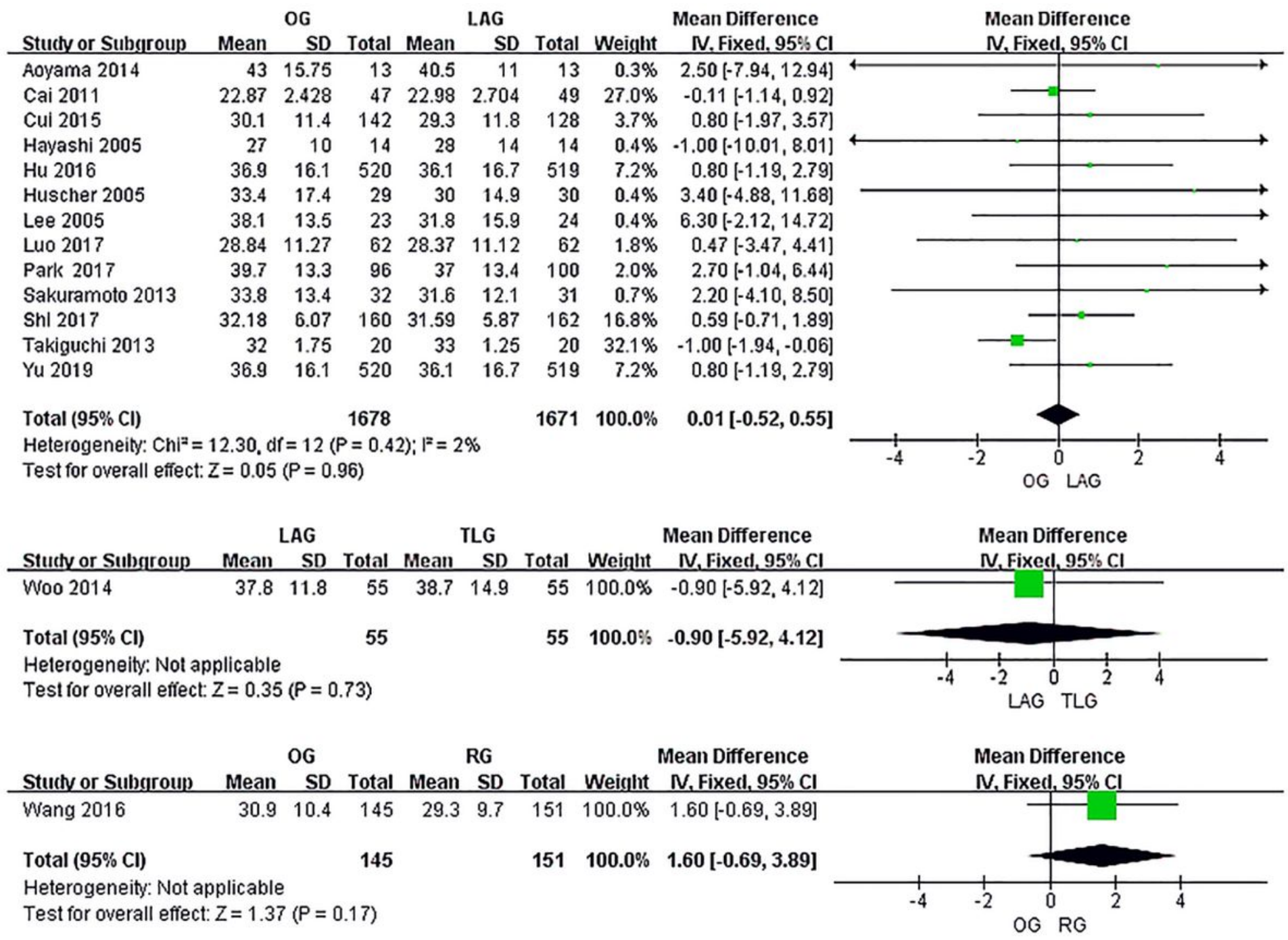




\section{Figure 5}

Forest plots of results with pair-wise meta-analysis for four gastrectomy of HLNs.

\section{Rank Probability}

Rank 1 is best, rank $\mathrm{N}$ is worst.

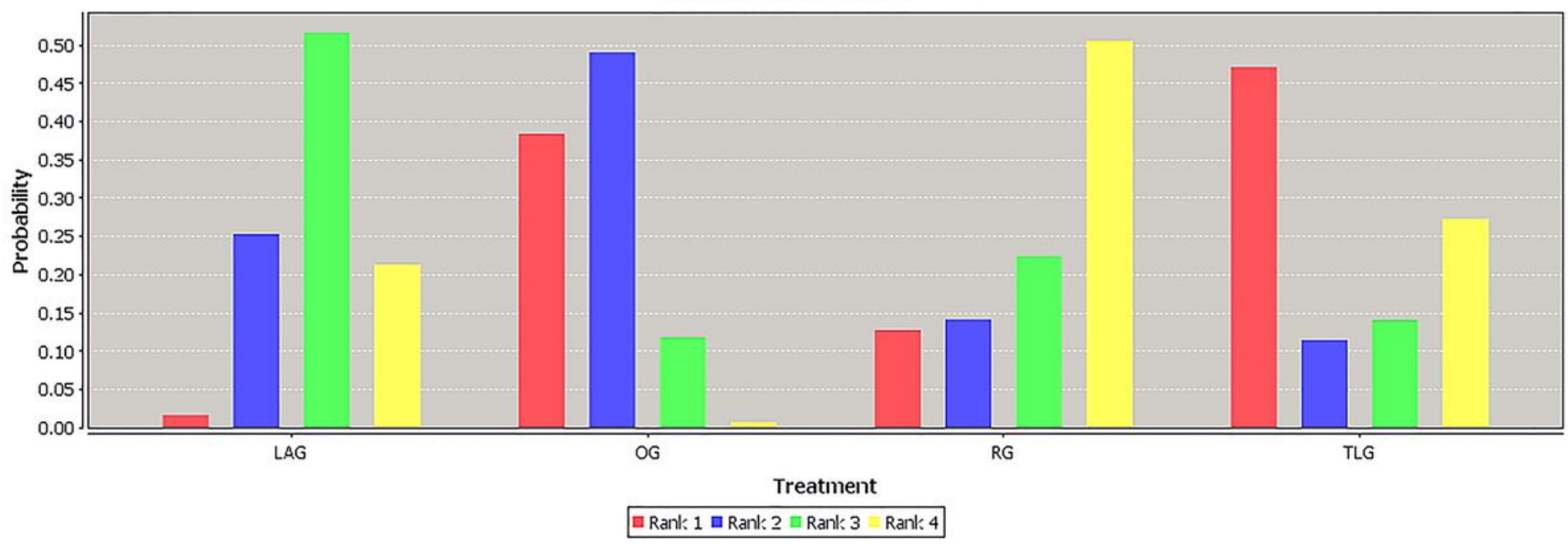

\section{Figure 6}

Ranking of treatments in the number of HLNs.

Random sequence generation (selection bias)

Allocation concealment (selection bias)

Blinding of participants and personnel (performance bias)

Blinding of outcome assessment (detection bias)

Incomplete outcome data (attrition bias)

Selective reporting (reporting bias)
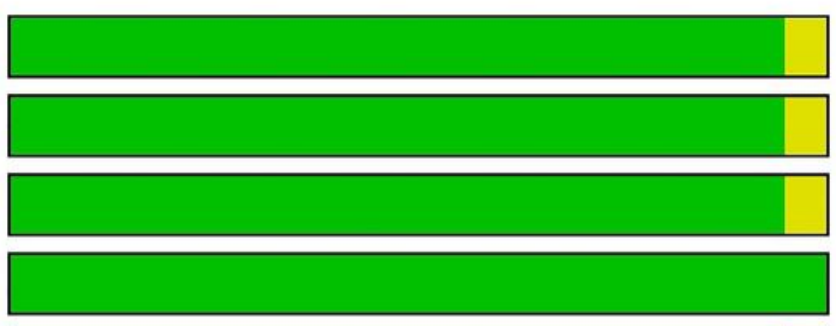

Other bias
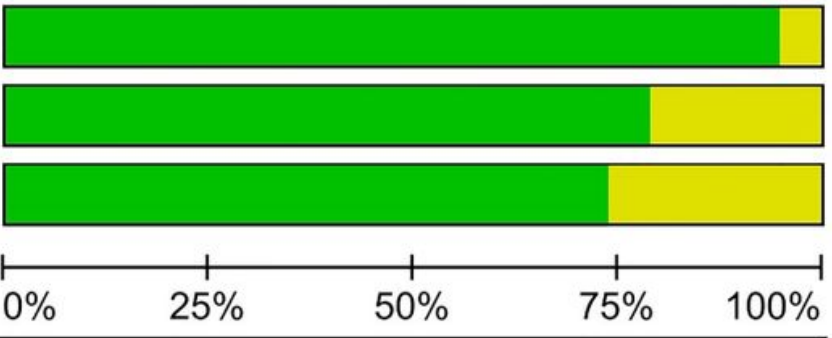

\section{Figure 7}

Risk of bias graph for all studies included. 


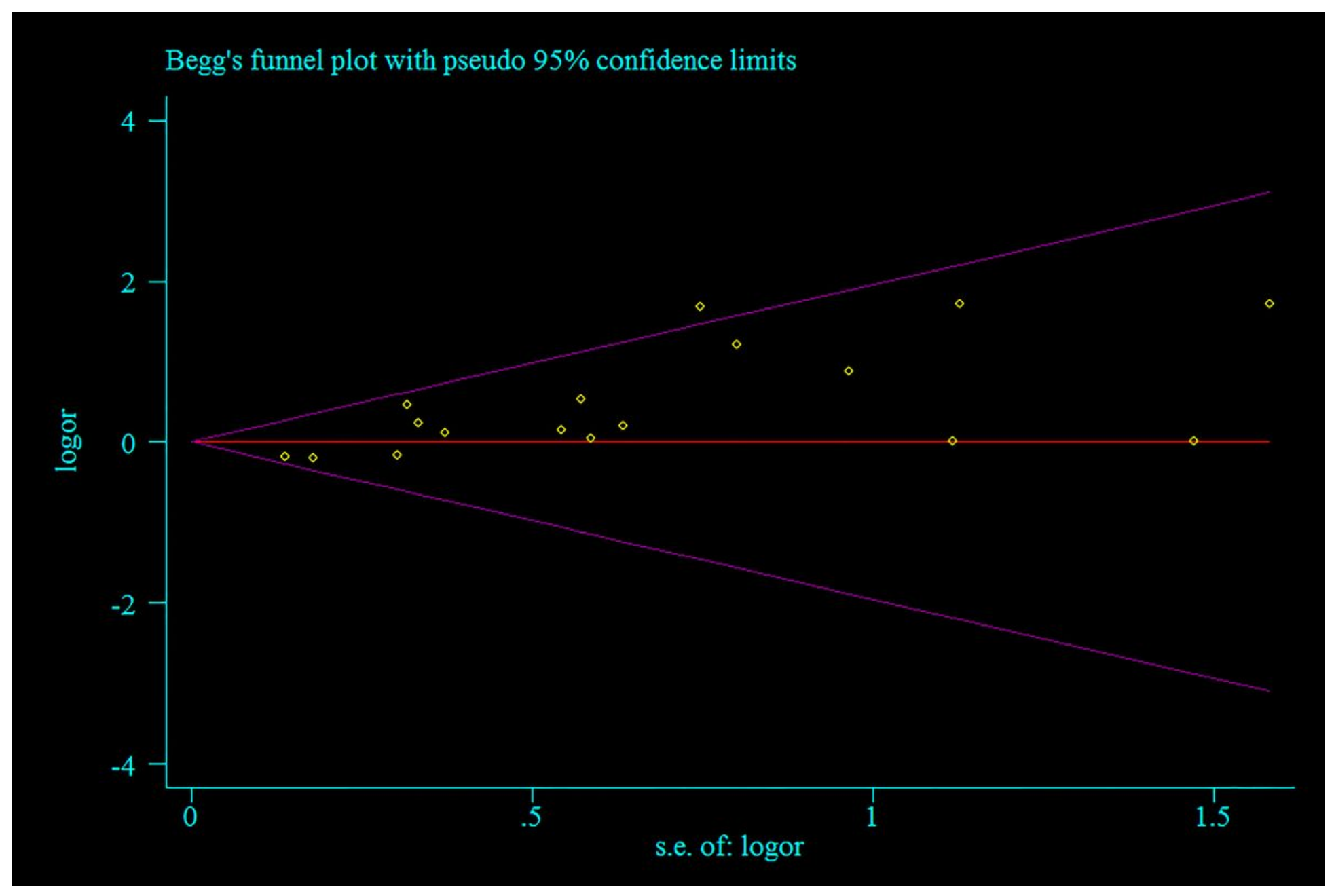

Figure 8

Begg's funnel plot. 
Meta-analysis estimates, given named study is omitted
| Lower CI Limit
o Estimate
| Upper CI Limit

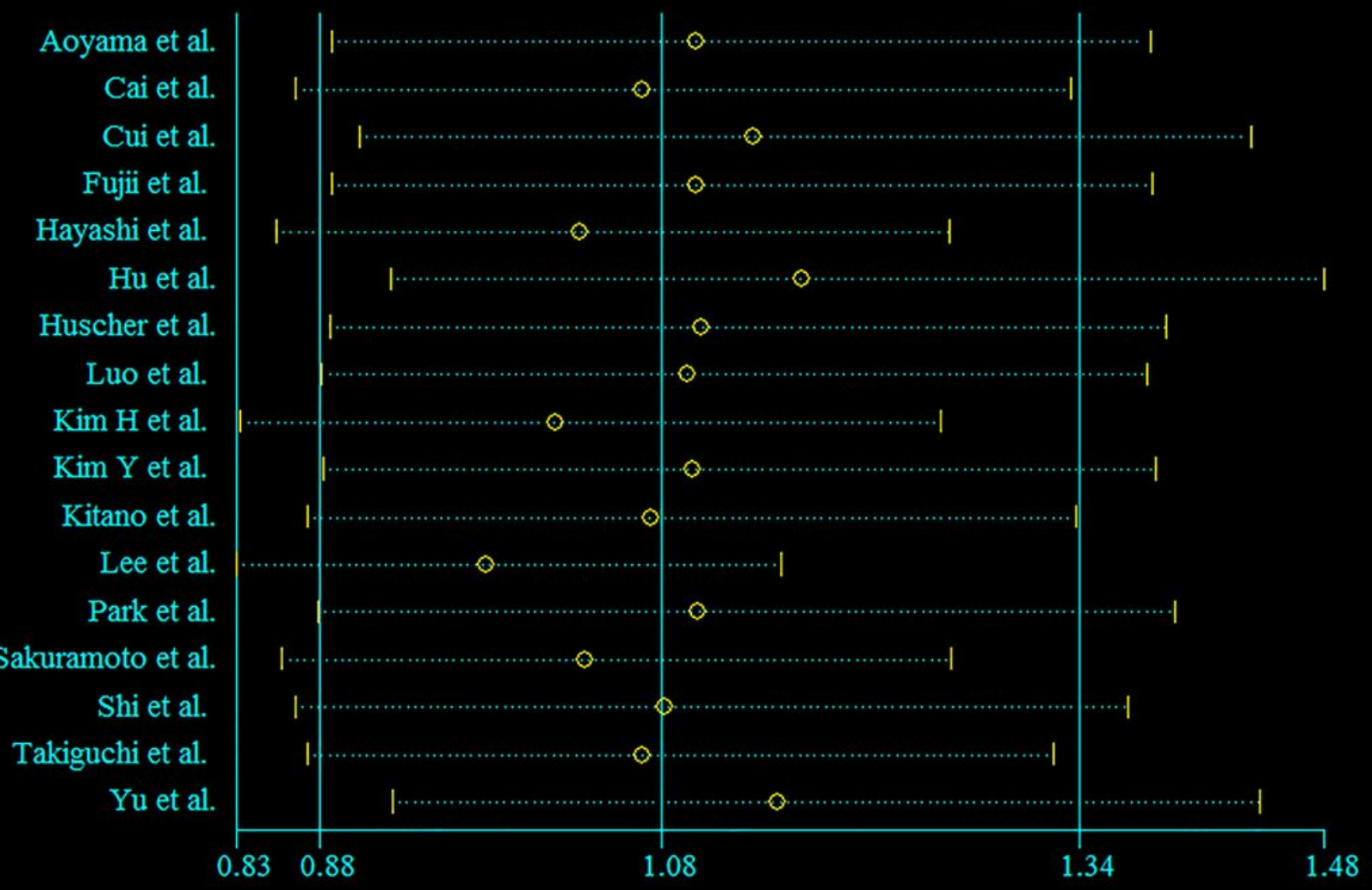

\section{Figure 9}

Sensitivity analysis for the group with low heterogeneity.

\section{Supplementary Files}

This is a list of supplementary files associated with this preprint. Click to download.

- PRISMA2009checklist.pdf 